\title{
Radiotherapy for cervical cancer: Chilean consensus of the Society of Radiation Oncology
}

\author{
Felipe Carvajal $^{1,3}$, Claudia Carvajal ${ }^{1}$, Tomás Merino ${ }^{4,5}$, Verónica López ${ }^{1}$, Javier Retamales ${ }^{1}$, \\ Evelyn San Martín ${ }^{2}$, Freddy Alarcón ${ }^{1}$, Mónica Cuevas $^{1}$, Francisca Barahona ${ }^{1}$, Ignacio Véliz ${ }^{1}$, \\ Juvenal A. Ríos 6 , Sergio Becerra ${ }^{5}$
}

\author{
${ }^{1}$ Departamento de Radio Oncología, Instituto Nacional del Cáncer, Santiago, Chile \\ ${ }^{2}$ Departamento de Radio Oncología, Hospital Clínico de Magallanes, Punta Arenas, Chile \\ ${ }^{3}$ Departamento de Oncología Básico Clínica, Facultad de Medicina, Universidad de Chile, Santiago, Chile \\ ${ }^{4}$ Departamento de Hemato-Oncolgía. Pontificia Universidad Católica de Chile, Santiago, Chile \\ ${ }^{5}$ Departamento del Cáncer, Ministerio de Salud, Santiago, Chile \\ ${ }^{6}$ Programas para el Futuro, Facultad de Estudios Interdisciplinarios, y Escuela de Medicina, Facultad de Ciencias, Universidad Mayor, \\ Santiago, Chile
}

\begin{abstract}
Background: Cervical cancer is a public health problem in Latin America. Radiotherapy plays a fundamental role both as definitive or adjuvant treatment. There are important intra and inter-country differences regarding access and availability of radiotherapy facilities in this region.

The aim of a study was to standardize the basic clinical and technical criteria for the radiation treatment of patients with CC in Chile and provide a guide for Latin American Radiation Oncologists.

Materials and methods: Forty-one expert radiation oncologists from the Chilean Radiation Oncology Society made a consensus using the Delphi methodology.

Results: There was a high degree of agreement for each of the recommendations. Those with the lowest percentage were related to the definition of the conformal $3 \mathrm{D}$ technique as the standard for definitive external radiotherapy (81\%) and the criteria for extended nodal irradiation (85\%).

Conclusions: These recommendations present an updated guide for radiotherapy treatment of patients with cervical cancer for Latin America. Those should be implemented according to local resources of each institution.

Key words: uterine cervical neoplasms; radiotherapy; brachytherapy; consensus

Rep Pract Oncol Radiother 2021;26(2):291-302
\end{abstract}

\section{Introduction}

Cervical cancer (CC) is an important problem for public health in Latin America. According to GLOBOCAN, it's the sixth most frequent malignancy in Chilean's women, with incidence of 12.2/100,000 women, (age-adjusted rate) and mortality of 5.0/100,000 [1]. Early diagnosis screening with the Papanicolaou test is essential but the cov- erage of the Chilean population is only about $59 \%$, with zones that fluctuate between $72.2 \%$ (Los Ríos's region) and 45.5\% (Antofagasta's Region) [2]. Radiation therapy plays a fundamental role in CC for the primary (definitive) and adjuvant (postoperative) settings, with treatment schemes that combine external beam radiotherapy (EBRT), high dose rate (HDR) or low dose rate (LDR) brachytherapy, and concomitant chemotherapy (CCT) [2]. The acceler- 
ated evolution of the technology in imaging and radiation equipment during the last decades has implied a paradigm shift in different types of cancer, including the gynecological ones. Latin America is a region with different realities within and between countries regarding access and availability of radiotherapy facilities [3-5]; therefore, it is of high importance to have a regional consensus to define treatment strategies. The present consensus aims to standardize the basic clinical and technical criteria for the radiation treatment of patients with CC in Chile and provide a guideline for Latin American Radiation Oncologists.

\section{Materials and methods}

The board of the Chilean Society of Radiation Oncology (SOCHIRA) convened national experts in radiation oncology with experience in the management of patients with CC. To generate a national consensus. We used a three phase modified Delphi method [6].

The first phase was an online survey developed to ask for the management of different clinical cases and common management practices. We distributed the survey by e-mail to national specialists using a digital platform. Subsequently, national specialists were called to make a review of the literature, including PUBMED database, recent publications in conferences of the specialty and recommendations of international groups in order to prepare proposals for recommendations based on the evidence and consider the opinions or comments provided by 44 national experts through the online survey previously indicated.
In the second phase, the proposal for final recommendations based on the answers from the first phase was distributed to 89 specialists in oncological radiotherapy from the country.

Participants had to specify anonymously their level of agreement to the statements using a 5-point Likert's scale [7]: $1=$ Strongly disagree, $2=$ Disagree, $3=$ Neither agree nor disagree, $4=$ Agree, $5=$ Strongly agree.

The consensus in a recommendation was established if more than $66 \%$ of the answers were 1 and 2 , or 4 and 5 for each question, according the suggestions of the literature $[6,8]$. Finally, the third phase was carried out in person to review the results of online voting and define consensus on those statements that reached only partial consensus in phase 2. Degrees of recommendation and levels of evidence were assigned to each recommendation [9] (Tab. 1). To maintain agreement with pivotal studies and avoid confusion, the use of the 2009 version of the FIGO classification in CC was maintained [10].

\section{Results and Discussion}

41 of 89 radiation oncologists completed the distributed survey with recommendations for its validation, 33 of them routinely treat patients with CC. Within this group, the median number of patients with CC treated by each radiation oncologist was 30 per year. Of a total of 19 radiation oncologists dedicated to gynaecology cancer in Chile, 17 responded to the survey (90\%). The median number of CC patients treated by each of these experts was 60 per year.

Table 1. Level of evidence and grade of recommendation determined by the technical committee of Explicit Guarantees in Health (GES), Ministry of Health, Chile

\begin{tabular}{|c|c|}
\hline Grade & Description \\
\hline \multirow[b]{2}{*}{ A } & Highly recommended: Based on good quality studies \\
\hline & $\begin{array}{l}\text { Systematic reviews of randomized clinical trials, randomized clinical trials, other systematic reviews with or without meta- } \\
\text { analysis, health technology assessment reports. }\end{array}$ \\
\hline \multirow{2}{*}{ B } & Recommended: Based on moderate quality studies \\
\hline & Randomized studies with methodological limitations or other forms of non-randomized controlled studies. \\
\hline $\mathrm{C}$ & $\begin{array}{l}\text { Recommendation based exclusively on expert opinion or descriptive studies, case series, case reports or other uncontrolled } \\
\text { studies with a high potential for bias. }\end{array}$ \\
\hline \multirow[b]{2}{*}{ I } & Insufficient information \\
\hline & $\begin{array}{l}\text { The available studies do not allow to establish the effectiveness or benefit / harm balance of the intervention, there are no } \\
\text { studies on the subject or there is not enough consensus to consider that the intervention is supported by practice. }\end{array}$ \\
\hline BP & Recommendation based on the experience and practice of a group of experts. \\
\hline
\end{tabular}


The recommendations are summarized in the Table 2. The detail is available in Appendix.

\section{Questions and brief analysis of evidence}

There are several international clinical guidelines on CC. We published here the first one, to our knowledge, developed in Latin America. There are consensuses that are oriented to the delineation of target volumes [11-13], specific topics in
BT [14-17] and others related to multidisciplinary management of cervical CC [18-20]. Recently, the American Society for Radiation Oncology (ASTRO) has published a consensus focused on RT developed using a Delphi method with recommendations consistent with ours [21]. We focused on defining a desirable technical maximum and a required minimum in order to consider the existing differences and limitations in Chile and Latin America. In addition, we include a guideline regarding the indication of extended field radio-

Table 2. Recommendations of the SOCHIRA for radiotherapy treatment in cervical cancer

\begin{tabular}{|c|c|c|c|}
\hline Recommendations & $\begin{array}{l}\text { Grade of } \\
\text { recommendation }\end{array}$ & $\begin{array}{l}\text { Level of } \\
\text { evidence }\end{array}$ & $\begin{array}{l}\text { Percentage of } \\
\text { agreement }\end{array}$ \\
\hline $\begin{array}{l}\text { The use of adjuvant EBRT is recommended in the following situations: WITHOUT } \\
\text { platinum based CCT: Sedlis criteria: 1) ILV+ and deep third, any T 2) ILV+ middle } \\
\text { third and tumor larger than } 2 \mathrm{~cm} \text { 3) ILV + superficial third and tumors greater than or } \\
\text { equal to } 5 \mathrm{~cm} \text { 4) ILV-, middle third and tumor of } 4 \mathrm{~cm} \text { also 5) ILV+, deep third and } 4 \mathrm{~cm} \\
\text { tumor. WITH platinum based CCT: Peters criteria 1) lymphadenopathy (+) } \\
\text { 2) parametrium (+) 3) margin (+) }\end{array}$ & A & 1 & $98 \%$ \\
\hline $\begin{array}{l}\text { IMRT technique in adjuvant EBRT is recommended. Conventional } 3 D \text { technique is } \\
\text { a valid option, considerations of a higher acute and late toxicity must be taken }\end{array}$ & B & 1 & $86 \%$ \\
\hline $\begin{array}{l}\mathbf{4 5} \text { Gy in } \mathbf{2 5} \text { fractions is recommended as adjuvant schedule dose } \\
\text { Other accepted fractionation schedules are } 50.4 \text { Gy in } 28 \text { fractions, } 50 \text { Gy in } 25 \\
\text { fractions of } 2 \text { Gy day, } 46 \text { Gy in } 23 \text { fractions }\end{array}$ & B & 2 & $95 \%$ \\
\hline $\begin{array}{l}\text { Routine use of brachytherapy as a boost dose in adjuvant setting is not } \\
\text { recommended. Its use can be considered in the case of a close or positive vaginal } \\
\text { margin, for a total EQD2 dose of } 65-70 \mathrm{~Gy}\end{array}$ & C & 4 & $90 \%$ \\
\hline $\begin{array}{l}\text { The use of definitive radiotherapy (EBRT plus brachytherapy) is recommended in } \\
\text { patients with an early stage (IB1, IIA1) in the case of surgical contraindication } \\
\text { or patient rejection }\end{array}$ & B & 1 & $100 \%$ \\
\hline $\begin{array}{l}\text { The use of definitive radiation therapy (external RT plus brachytherapy) with } \\
\text { concomitant chemotherapy is recommended in patients with an advanced stage: } \\
\text { IB2 and } \geq \text { IIA2 to IVA }\end{array}$ & A & 1 & $100 \%$ \\
\hline $\begin{array}{l}\text { 3D conformal technique is recommended as standard for definitive radiotherapy } \\
\text { IMRT is an option to consider given its theoretical and clinical benefits derived from } \\
\text { other pelvic neoplasms, with the use of an appropriate IGRT protocol } \\
\text { and consideration of internal movements }\end{array}$ & B & 3 & $81 \%$ \\
\hline $\begin{array}{l}\mathbf{4 5} \text { Gy in } \mathbf{2 5} \text { fractions is recommended as definitive radiotherapy schedule dose } \\
\text { Other accepted fractionation schedules are } 50.4 \text { Gy in } 28 \text { fractions, } 50 \text { Gy in } 25 \\
\text { fractions, } 46 \text { Gy in } 23 \text { fractions }\end{array}$ & B & 2 & $95 \%$ \\
\hline $\begin{array}{l}\text { Total treatment time } \leq \mathbf{5 0 - 5 6} \text { days is recommended } \\
\text { Early referral to BT is recommended }\end{array}$ & A & 2 & $100 \%$ \\
\hline $\begin{array}{l}\text { Parametrial boost with external radiation therapy is not recommended. For its } \\
\text { omission consider: 1) Clinical and imaging evaluation of parametrial involvement. } \\
\text { 2) To have the ability to perform interstitial brachytherapy if required } \\
\text { In case of not complying with the previous points, it is accepted to perform } \\
\text { a sequential parametrial boost up to } 54-59.4 \text { Gy or its equivalent with integrated } \\
\text { simultaneous boost, considering the increased risk of acute and mainly late } \\
\text { complications }\end{array}$ & A & 2 & $93 \%$ \\
\hline $\begin{array}{l}\text { The inclusion of lumbo-aortic (LAo) lymph nodes is recommended in selected } \\
\text { high-risk patients, according to the EMBRACE II protocol: } \geq 1 \text { common iliac lymph } \\
\text { node matastases, } \geq 3 \text { pelvic lymph node matastases. In the case of lymph node } \\
\text { metastases in Lao, it should be extended to at least } 3 \mathrm{~cm} \text { above the highest }\end{array}$ & B & 3 & $85 \%$ \\
\hline
\end{tabular}


Table 2. Recommendations of the SOCHIRA for radiotherapy treatment in cervical cancer

\begin{tabular}{|c|c|c|c|}
\hline Recommendations & $\begin{array}{c}\text { Grade of } \\
\text { recommendation }\end{array}$ & $\begin{array}{l}\text { Level of } \\
\text { evidence }\end{array}$ & $\begin{array}{c}\text { Percentage of } \\
\text { agreement }\end{array}$ \\
\hline $\begin{array}{l}\text { Sequential Boost to pelvic lymph node macroscopic disease is recommended up } \\
\text { to } 55-60 \text { Gy or its equivalent with integrated simultaneous boost (SIB) (preferably SIB } \\
\text { with IMRT technique) } \\
\text { In LAo lymph nodes macroscopic disease, without evidence of systemic spread } \\
\text { on PET/CT, sequential boost of up to } 60 \text { Gy or its equivalent with integrated } \\
\text { simultaneous boost is recommended, ideally using the IMRT technique in both cases }\end{array}$ & B & 2 & $100 \%$ \\
\hline $\begin{array}{l}\text { The use of HDR technique is recommended } \\
\text { LDR technique is accepted as an option }\end{array}$ & A & 2 & $97 \%$ \\
\hline $\begin{array}{l}\text { Brachytherapy treatment planning based on 3D images (CT and/or MRI) with } \\
\text { volumetric prescription and evaluation is recommended } \\
\text { Use applicator adapted to residual disease or anatomy of the patient. Interstitial } \\
\text { brachytherapy is recommended if required } \\
2 \mathrm{D} \text { dosimetry prescription A point and report rectal and bladder point accepted. } \\
\text { In case of using the LDR technique, a prescription should be made for point A } \\
\text { and a report of the rectal and bladder point should be made }\end{array}$ & A & 2 & $98 \%$ \\
\hline $\begin{array}{l}\text { It is recommended to have an initial pelvic MRI evaluation (before EBRT) and one } \\
\text { immediately before brachytherapy. It can be a simulation MRI or fused diagnostic } \\
\text { MRI. Prioritize MRI prior to brachytherapy. If there is no access to MRI, treatment based } \\
\text { on simulation CT or ultrasound performed by an expert is accepted }\end{array}$ & A & 2 & $98 \%$ \\
\hline
\end{tabular}

EBRT — external beam radiotherapy; CCT — concomitant chemotherapy; ILV — ipsilateral lung volume IMRT — intensity modulated radiation therapy; EQD2 - equivalent dose at fractionation of 2 Gy; IGRT — image-guided radiation therapy; HDR — high dose rate; LDR — low dose rate PET — positron emission tomography; $\mathrm{CT}$ - computed tomography; $\mathrm{MRI}$ - magnetic resonance imaging

therapy, parametrial boost, overall treatment time and the need to implement interstitial BT in faculties involved in the treatment of patients with CC. A review of literature related with our recommendations are presented below.

\section{What are the indications for adjuvant radiation therapy?}

Adjuvant radiotherapy (RT) in CC has been evaluated in different phase III clinical studies and meta-analyses, demonstrating that in patients with intermediate and high risk of recurrence there is a clear benefit with its use in terms of progression-free survival (PFS) and overall survival (OS) [22-26]. In relation to patients classified as intermediate risk based on the inclusion criteria of the GOG 92 study that considers lymph vascular invasion, depth of invasion and tumor size ("Sedlis criteria"), an increase in PFS was observed at 5 years of $53 \%$ to $62 \%$ when comparing adjuvant RT versus surgery alone, with less local and distant recurrence $[22,23]$. Regarding high-risk cases of postoperative recurrence, defined as those where there was compromise of lymph nodes, parametria, or surgical margin in the radical hysterectomy ("Peters criteria"), the GOG 109 study demonstrated benefits of platinum based radiochemotherapy (RQT) versus RT alone with improvement in 5-year OS from $66 \%$ to $80 \%$ and in 5-year PFS from $79 \%$ to $83 \%[24,25]$.

\section{Is intensity modulated radiation therapy (IMRT) better than conventional 3D treatment for adjuvant external beam radiotherapy?}

The RTOG 1203 study [27] is the only randomized clinical trial that has evaluated the comparison between IMRT technique and conventional 3D conformal. It randomized 289 patients to conventional 3D technique or IMRT in adjuvant setting, $75 \%$ without concomitant chemotherapy. Initial results showed a significant decrease in acute and late gastrointestinal and genitourinary toxicity reported by patients $[27,28]$.

\section{What is the appropriate dose}

\section{and fractionation in adjuvant setting?}

The dose and fractionation used in the different clinical studies is variable. The protocols of the pivotal studies used for exclusive adjuvant EBRT 46 to $50.4 \mathrm{~Gy}$ in 23 to 28 fractions [22, 23], and in GOG 109 study, planned RT to the pelvis in a scheme of $49.3 \mathrm{~Gy}$ in 29 fractions, adding a lumboaortic nodal field of 45 Gy in 25 fractions in case of compromised common iliac lymph nodes [24, 25]. Also, there are other studies that consider schemes from 
45 to 50.4 Gy between 1.8 and 2 Gy daily [29-31]. The IMRT protocol in adjuvant context (RTOG 1203) allows the use of 45 Gy or 50.4 Gy in fractions of 1.8 Gy daily depending on the researcher's preference. Approximately $60 \%$ of patients received 45 Gy in 25 fractions [27].

\section{Is the use of brachytherapy (BT) boost} recommended in the adjuvant setting?

Depending on the extent of surgical resection, the vaginal dome may be at higher risk of recurrence, but randomized clinical studies did not consider BT boost in addition to EBRT [22-25],with only retrospective reports of its use in the context of patients with positive margins [32]. Considering the lack of evidence, the American Brachytherapy Society (ABS) generated a consensus on its use recommending adjuvant $\mathrm{BT}$ in addition to EBRT with an equivalent dose close to $70 \mathrm{~Gy}$ in patients with close or compromised vaginal margins, with non-radical hysterectomy, large or deeply invasive tumors, parametrial involvement or extensive lymphovascular invasion [14].

\section{What are the indications for definitive radio(chemo)therapy?}

In early stages (stages FIGO I to IIA1 except IB2) the usual treatment is surgery, but it is important to highlight that definitive RT offers similar results in terms of survival and therefore can be offered as an oncological equivalent alternative. A prospective randomized study [33, 34] with 170 patients in each arm in stages I-II found that there were no differences in 5-year survival between exclusive RT and surgery.

In locally advanced stages (FIGO stages IB2 and IIA2 or higher), the evidence favors the use of definitive RTQT since the publication of the five classic randomized studies of the late $20^{\text {th }}$ century $[24,35-38]$ that motivated the NCI alert and the meta-analysis published a decade later with updated data from individual patients from 15 randomized studies [39] again giving robust support to definitive RTQT as standard treatment in advanced stages.

\section{Is IMRT better than conventional 3D treatment for definitive EBRT?}

Various retrospective [40-42] and prospective uncontrolled studies [43-45] and a meta-analysis
[46], have shown equivalence in oncological results and a significant decrease in acute and chronic toxicity both genitourinary and gastrointestinal in benefit of the IMRT technique. However, there are no published randomized clinical trials confirming the benefits of using IMRT compared to conventional $3 \mathrm{D}$ as definitive therapy.

\section{What is the appropriate dose and fractionation of the EBRT in definitive radiotherapy?}

The dose and fractionation used in different clinical studies during the EBRT phase is variable, including patients from 40.8 Gy in 24 fractions to $51 \mathrm{~Gy}$ in 30 fractions according to their FIGO stage [24, 35-38]. The American Brachytherapy Society guideline recommends $45 \mathrm{~Gy}$ in 25 fractions [15]. On the other hand, the current ESGO/ESTRO/ESP guideline recommends a dose of $45-50.4$ Gy in 1.8 Gy daily fractions $[18,47]$. Retrospective studies have shown that most of the tumor response in the EBRT phase occurs before 45 Gy [48]. Three extra fractions to reach 50.4 Gy provide little tumor control and, on the other hand, decrease the possibility of dose escalation during adaptive brachytherapy [48, 49. In this context, the GEC/ESTRO network in its EMBRACE studies [50] went from recommending a 45-50.4 Gy dose with EBRT (1.8 Gy daily fractions) to a $45 \mathrm{~Gy}$ dose in 25 fractions for all patients in the EMBRACE II protocol [51].

\section{Is there an overall treatment time that determines the best oncological outcome?}

The overall treatment time impact was demonstrated in studies prior to the concomitant chemotherapy era showing a pelvic control loss of 7-8\% per extra week [52-55]. Considering the above, the American Brachytherapy Society recommends that the total treatment time should not exceed 8 weeks [15]. This data has been corroborated at the concomitant chemotherapy era by the EMBRACE group who showed that, considering a median of 49 days of treatment, an extra week is equivalent to $1-2.5 \%$ local control loss depending on the size of the residual tumor volume. Considering the previous data, the EMBRACE II group recommends maintaining a total treatment time of $\leq 50$ days [56]. 


\section{What is the role of parametrial boost in definitive radiation therapy?}

Parametrial boost with EBRT has not been used routinely or standardized in clinical trials [24, 35-38]. It has been observed that its application leads to unpredictable doses at the tumor and the organs at risk [57] which can lead to a decrease in local control and increased toxicity. An Australian retrospective study evaluating the omission of external beam parametrial boost in patients with parametrial involvement defined by physical examination and magnetic resonance showed no difference in terms of local control compared to the group of patients without parametrial involvement [58]. In the last decade the trend has been to implement 3D image guided adaptive brachytherapy with parametrial boost application as needed at the brachytherapy planning, being the current recommendation of the GEC-ESTRO network. Current ESGO/ESTRO/ESP guidelines advise against the use of parametric treatment with external radiotherapy beyond 45-50.4 Gy [47].

\section{What is the role of extended field radiotherapy (lumboaortic area) in definitive radiotherapy?}

In cervical cancer patients it is estimated that the probability of pelvic and lumboaortic nodal involvement increases progressively as the disease stage progresses affecting overall survival (OS) and disease-free survival (DFS) [59]; therefore, adequate staging is essential for treatment planning. Current international guidelines consider FDG PET-CT as the preferred option for staging given its high specificity (approx. 90\%) and sensitivity (approx. 70\%) in patients with advanced local involvement $[18,60,61]$. The benefit of prophylactic extended field towards the lumboaortic region in patients without compromise in that zone has been evaluated in several studies (including EORTC 1988 and RTOG 7920), demonstrating contradictious improvement in OS and no benefit in other studies. However, treatment in these studies was not performed with concomitant chemotherapy, so the actual benefit may be overestimated [62-65]. Regarding patients with compromised lumboaortic nodes, the contribution of extended field versus pelvic field is also controversial, since the clinical trial that studied it (RTOG 9001) did not include $\mathrm{CT}$ in patients with extended field but it did for those treated exclusively with a pelvic field $[37,66]$. More current retrospective studies report benefit in DFS and local control with acceptable toxicity [67], but it's not clear what the characteristics of patients who should receive this modality are. Vargo et al. showed that extended field IMRT achieves 95\% control in lumboaortic-negative patients and $89 \%$ in lumboaortic-positive patients [68]. The EMBRACE group showed that at the time of diagnosis $47 \%$ of the patients had nodal involvement, mainly in the pelvis (internal, external and common iliac region), but nodal recurrences after treatment generally occurred in the lumboaortic region constituting $69 \%$ of all nodal failures. Of these failures, $78 \%$ had not received RT in that region, so identifying high-risk groups to treat is essential [50]. Due to all of the above, the EMBRACE II group defined a high-risk lumboaortic recurrence or distance failure group: those patients who have 1 or more common iliac lymphadenopathy or those with the presence of 3 or more pelvic lymphadenopathy, with the aim to study the role of lumboaortic RT in those who meet these requirements.

In cases with a lumboaortic involment, a paraortic field covering at least $3 \mathrm{~cm}$ cephalic to the adenopathy will be planned.

It's clear that the available evidence is not categorical for the use of extended lumboaortic field, so the proposed plan is to follow the rationale of the main research group active in the subject (EMBRACE II) [50].

\section{Is there an optimal dose to deliver in macroscopic node disease?}

There are retrospective studies that have evaluated the dose necessary to achieve adequate control of macroscopic lymph node disease [69-71]. These studies, have shown that a dose of $\geq 57.5 \mathrm{~Gy}$ achieves a better oncological outcome. It is important to consider, in this context, that brachytherapy also provides doses to the lymph node areas, mainly to the iliac-obturator region, being able to add up to $5 \mathrm{~Gy}$ on average. In the case of lumbo-aortic lymphadenopathy, extended field irradiation has been performed with a dose of $45 \mathrm{~Gy}$ in 25 fractions of 1.8 Gy [37, 62, 63, 65-67]. Boost dose to the lymphadenopathy have been performed with doses of up to $60 \mathrm{~Gy}$ in conventional fractionation, considering studies that show a better nodal control with doses $\geq 57.5 \mathrm{~Gy}$ [69]. For pelvic macroscopic 
node disease, current ESTRO guidelines recommend a dose of 55-60 Gy considering the contribution of brachytherapy [47].

\section{Is HDR brachytherapy technique better than LDR brachytherapy?}

Both techniques are similar from the perspective of oncological outcome and toxicity of the treatment. However, the HDR technique has some advantages over LDR [72-76] as it:

- allows better positioning of the applicator in the patient during the treatment session;

- enables image-guided treatment;

- allows an outpatient treatment, unlike LDR brachytherapy that requires hospitalization (1-3 days);

- decreases the risk of complications due to immobilization of the patient;

- decreases the risk of radiation exposure to personnel;

- decreases the risk of radioactive accidents.

In this context, the International Atomic Ener-

gy Organization has had among its objectives that radiotherapy faculty have a transition from LDR brachytherapy to HDR [77].

\section{Is $3 \mathrm{D}$ treatment planning better than $2 \mathrm{D}$ in brachytherapy?}

Image-guided (3D) treatment allows evaluating the response to treatment during radiotherapy and adapting the volumes to be treated with brachytherapy. The STIC Trial, a non-randomized prospective study, shows that a 3D based treatment planning in cervical cancer allows better local control and lower toxicity rate than $2 \mathrm{D}$ dosimetry [78]. Currently, the Groupe Européen de Curiethérapie of the European Society for Radiation Oncology (GEC-ESTRO) recommends the Magnetic Resonance-guided Brachytherapy technique [16]. In 2008, the GEC-ESTRO began the study "International Study on MRI-Based Brachytherapy in Cervical Cancer" (EMBRACE) [50] reaching the recruitment of $>1,300$ patients in 27 countries in 2015. Pending its results, in 2010 the GEC-ESTRO started the retrospective study RetroEMBRACE, whose data shows that the local control at 5 years is $89 \%$. The concept of adaptive radiation therapy is focused on the volume of the primary tumor (GTV-T) and how it changes during RQT [79-81]. To achieve adequate doses, the combination of intracavitary and interstitial applicators
(IC/IS) is essential in large tumors, seeking to increase the dose in tumor tissue without increasing the toxicity of organs at risk (OAR) [82-85].

\section{What is the contribution of 3D images for the brachytherapy treatment planning?}

Sectional images (CT or MRI) provide valid and reliable information on the extent and configuration of individual tumors and their topography, making it easier to define the volumes to be treated (compared to clinical examinations without imaging support). By providing greater precision regarding the extension and spatial arrangement of the target, 3D images allow to increase the treatment dose in high-risk areas, protecting organs at risk near the tumor. The main advantage of MRI is its superior quality in the representation of soft tissues; therefore, when it is available, MRI is the imaging method of choice as it allows better differentiation between tissues, estimating parametrial involvement and tumor size $[16,17,86-90]$.

\section{Conclusion}

The recommendations presented are the result of the discussion of the evidence among national gynaecological radiotherapy specialists. Radiotherapy continues to play a fundamental role in the curative treatment of cervical cancer, whether as definitive therapy or adjunctive to surgery, concomitant or not with chemotherapy. To optimize the management of this pathology, it is recommended that new diagnostic modalities, such as PET-CT and MRI which allow a better selection of patients who will benefit from radiotherapy treatment with curative intent, should be incorporated as well as planning and adaptation of the treatment corrected. The optimal treatment should be carried out in a period not exceeding 56 days and, ideally, in less than 50 days, which is a quality standard that requires to articulate human resources in comprehensive cancer centres and foster homes, among others. Regarding the radiotherapy technique, the use of IMRT is recommended as a treatment option when to reduce the dose to organs at risk. The need to migrate to an adaptive 3D image based brachytherapy technique with an interstitial support option is emphasized. These recommendations are available to standardize and improve clinical practice and must 
be adapted to each radiotherapy centre according to its local reality.

\section{Conflict of interest}

The authors (F.C., C.C., T.M., V.L., J.R., E.S.M., F.A., M.C., F.B., I.V., J.A.R., S.B.) declare that have no conflicts of interest to be declared.

\section{Funding}

The authors (F.C., C.C., T.M., V.L., J.R., E.S.M., F.A., M.C., F.B., I.V., J.A.R., S.B.) declare that have no sponsorship/funding to be declared.

\section{Financial/other relationships}

The authors (F.C,. C.C., T.M., V.L., J.R., E.S.M., F.A., M.C., F.B., I.V., J.A.R., S.B.) declare that have no financial or other relationships to be declared.

\section{Author contributions}

F.C., C.C., T.M. were involved in the conception, design, preparation and final revision of the manuscript and participated in the collection and interpretation of data. V.L., J.R., E.S.M., F.A., M.C., F.B., I.V., J.A.R. were involved in the preparation of the first draft and critically revised the final version of the manuscript. S.B. Revised critically the final version of the manuscript. All authors read and approved the final version of the manuscript to be published and are accountable for all aspects of this work.

\section{Acknowledgements}

Acknowledgements to all members of Chilean Society of Radiation Oncology.

\section{References}

1. GLOBOCAN statics. http://gco.iarc.fr/today/ home (04/27/2020).

2. Ministerio de Salud. Guía Clínica AUGE Cáncer Cérvico Uterino. Minsal, Santiago 2015.

3. Bishr MK, Zaghloul MS. Radiation Therapy Availability in Africa and Latin America: Two Models of Low and Middle Income Countries. Int J Radiat Oncol Biol Phys. 2018; 102(3): 490-498, doi: 10.1016/j.jijrobp.2018.06.046, indexed in Pubmed: 30005945.

4. Zubizarreta EH, Poitevin A, Levin CV. Overview of radiotherapy resources in Latin America: a survey by the International Atomic Energy Agency (IAEA). Radiother Oncol. 2004; 73(1): 97-100, doi: 10.1016/j.radonc.2004.07.022, indexed in Pubmed: 15465152.

5. Guedea F, Ventura M, Londres B, et al. Overview of brachytherapy resources in Latin America: a patterns-of-care survey. Brachytherapy. 2011; 10(5): 363-368, doi: 10.1016/j. brachy.2010.12.003, indexed in Pubmed: 21296032.
6. Puglisi F, Bisagni G, Ciccarese M, et al. A Delphi consensus and open debate on the role of first-line bevacizumab for HER2-negative metastatic breast cancer. Future Oncol. 2016; 12(22): 2589-2602, doi: 10.2217/fon-2016-0295, indexed in Pubmed: 27443691.

7. Likert R. A technique for the measurement of attitudes. Arch Psychol . 1932; 22(140): 55-55.

8. Mohile SG, Velarde C, Hurria A, et al. Geriatric AssessmentGuided Care Processes for Older Adults: A Delphi Consensus of Geriatric Oncology Experts. J Natl Compr Canc Netw. 2015; 13(9): 1120-1130, doi: 10.6004/jnccn.2015.0137, indexed in Pubmed: 26358796.

9. Manterola C, Asenjo-Lobos C, Otzen T. Jerarquización de la evidencia: Niveles de evidencia y grados de recomendación de uso actual. Rev Chil Infectol. 2014; 31(6): 705-718, doi: 10.4067/s0716-10182014000600011.

10. FIGO Committee on Gynecologic Oncology. FIGO staging for carcinoma of the vulva, cervix, and corpus uteri. Int J Gynaecol Obstet. 2014; 125(2): 97-98, doi: 10.1016/j. ijgo.2014.02.003, indexed in Pubmed: 24630859.

11. Small W, Mell LK, Anderson P, et al. Consensus guidelines for delineation of clinical target volume for intensitymodulated pelvic radiotherapy in postoperative treatment of endometrial and cervical cancer. Int J Radiat Oncol Biol Phys. 2008; 71(2): 428-434, doi: 10.1016/j. ijrobp.2007.09.042, indexed in Pubmed: 18037584.

12. Lim K, Small W, Portelance L, et al. Gyn IMRT Consortium. Consensus guidelines for delineation of clinical target volume for intensity-modulated pelvic radiotherapy for the definitive treatment of cervix cancer. Int J Radiat Oncol Biol Phys. 2011; 79(2): 348-355, doi: 10.1016/j. ijrobp.2009.10.075, indexed in Pubmed: 20472347.

13. Toita T, Ohno T, Kaneyasu Y, et al. JCOG Radiation Therapy Study Group. A consensus-based guideline defining clinical target volume for primary disease in external beam radiotherapy for intact uterine cervical cancer. Jpn J Clin Oncol. 2011; 41(9): 1119-1126, doi: 10.1093/jjco/hyr096, indexed in Pubmed: 21875938.

14. Small W, Beriwal S, Demanes DJ, et al. American Brachytherapy Society. American Brachytherapy Society consensus guidelines for adjuvant vaginal cuff brachytherapy after hysterectomy. Brachytherapy. 2012; 11(1): 58-67, doi: 10.1016/j.brachy.2011.08.005, indexed in Pubmed: 22265439.

15. Viswanathan AN, Thomadsen B. American Brachytherapy Society Cervical Cancer Recommendations Committee, American Brachytherapy Society. American Brachytherapy Society consensus guidelines for locally advanced carcinoma of the cervix. Part I: general principles. Brachytherapy. 2012; 11(1): 33-46, doi: 10.1016/j. brachy.2011.07.003, indexed in Pubmed: 22265436.

16. Haie-Meder C, Pötter R, Van Limbergen E, et al. Gynaecological (GYN) GEC-ESTRO Working Group. Recommendations from Gynaecological (GYN) GEC-ESTRO Working Group (I): concepts and terms in 3D image based 3D treatment planning in cervix cancer brachytherapy with emphasis on MRI assessment of GTV and CTV. Radiother Oncol. 2005; 74(3): 235-245, doi: 10.1016/j. radonc.2004.12.015, indexed in Pubmed: 15763303.

17. Dimopoulos JCA, Petrow P, Tanderup K, et al. Recommendations from Gynaecological (GYN) GEC-ESTRO Working Group (IV): Basic principles and parameters for MR imaging within the frame of image based adaptive cervix 
cancer brachytherapy. Radiother Oncol. 2012; 103(1): 113-122, doi: 10.1016/j.radonc.2011.12.024, indexed in Pubmed: 22296748.

18. Cibula D, Pötter R, Planchamp F, et al. The European Society of Gynaecological Oncology/European Society for Radiotherapy and Oncology/European Society of Pathology Guidelines for the Management of Patients with Cervical Cancer. Virchows Arch. 2018; 472(6): 919-936, doi: 10.1007/s00428-018-2362-9, indexed in Pubmed: 29725757.

19. Lim MC, Lee M, Shim SH, et al. Practice guidelines for management of cervical cancer in Korea: a Korean Society of Gynecologic Oncology Consensus Statement. J Gynecol Oncol. 2017; 28(3): e22, doi: 10.3802/jgo.2017.28.e22, indexed in Pubmed: 28382794.

20. Chopra SJ, Mathew A, Maheshwari A, et al. National Cancer Grid of India Consensus Guidelines on the Management of Cervical Cancer. J Glob Oncol. 2018; 4: 1-15, doi: 10.1200/ JGO.17.00152, indexed in Pubmed: 30085891.

21. Chino J, Annunziata CM, Beriwal S, et al. Radiation Therapy for Cervical Cancer: Executive Summary of an ASTRO Clinical Practice Guideline. Pract Radiat Oncol. 2020; 10(4): 220-234, doi: 10.1016/j.prro.2020.04.002, indexed in Pubmed: 32473857.

22. Sedlis A, Bundy BN, Rotman MZ, et al. A randomized trial of pelvic radiation therapy versus no further therapy in selected patients with stage IB carcinoma of the cervix after radical hysterectomy and pelvic lymphadenectomy: A Gynecologic Oncology Group Study. Gynecol Oncol. 1999; 73(2): 177-183, doi: 10.1006/gyno.1999.5387, indexed in Pubmed: 10329031.

23. Rotman M, Sedlis A, Piedmonte MR, et al. A phase III randomized trial of postoperative pelvic irradiation in Stage IB cervical carcinoma with poor prognostic features: follow-up of a gynecologic oncology group study. Int J Radiat Oncol Biol Phys. 2006; 65(1): 169-176, doi: 10.1016/j. ijrobp.2005.10.019, indexed in Pubmed: 16427212.

24. Peters WA, Liu PY, Barrett RJ, et al. Concurrent chemotherapy and pelvic radiation therapy compared with pelvic radiation therapy alone as adjuvant therapy after radical surgery in high-risk early-stage cancer of the cervix. J Clin Oncol. 2000; 18(8): 1606-1613, doi: 10.1200/ JCO.2000.18.8.1606, indexed in Pubmed: 10764420.

25. Monk BJ, Wang J, Im S, et al. Gynecologic Oncology Group, Southwest Oncology Group, Radiation Therapy Oncology Group. Rethinking the use of radiation and chemotherapy after radical hysterectomy: a clinical-pathologic analysis of a Gynecologic Oncology Group/Southwest Oncology Group/Radiation Therapy Oncology Group trial. Gynecol Oncol. 2005; 96(3): 721-728, doi: 10.1016/j. ygyno.2004.11.007, indexed in Pubmed: 15721417.

26. Rogers L, Siu SS, Luesley D, et al. Radiotherapy and chemoradiation after surgery for early cervical cancer. Cochrane Database Syst Rev. 2012(5): CD007583, doi: 10.1002/14651858.CD007583.pub3, indexed in Pubmed: 22592722.

27. Klopp AH, Yeung AR, Deshmukh S, et al. Patient-Reported Toxicity During Pelvic Intensity-Modulated Radiation Therapy: NRG Oncology-RTOG 1203. J Clin Oncol. 2018; 36(24): 2538-2544, doi: 10.1200/JCO.2017.77.4273, indexed in Pubmed: 29989857.

28. Yeung AR, Pugh S, Klopp AH, et al. IMRT Improves Late Toxicity Compared to Conventional RT: An Update on NRG
Oncology-RTOG 1203. Int J Radiat Oncol Biol Phys. 2019; 105(1): S50, doi: 10.1016/j.ijrobp.2019.06.480.

29. Song S, Song C, Kim HJ, et al. 20 year experience of postoperative radiotherapy in IB-IIA cervical cancer patients with intermediate risk factors: impact of treatment period and concurrent chemotherapy. Gynecol Oncol. 2012; 124(1): 63-67, doi: 10.1016/j.ygyno.2011.09.033, indexed in Pubmed: 22004904.

30. Hong JH, Tsai CS, Lai CH, et al. Postoperative low-pelvic irradiation for stage I-IIA cervical cancer patients with risk factors other than pelvic lymph node metastasis. Int J Radiat Oncol Biol Phys. 2002; 53(5): 1284-1290, doi: 10.1016/ s0360-3016(02)02831-6, indexed in Pubmed: 12128131.

31. Soisson AP, Soper JT, Clarke-Pearson DL, et al. Adjuvant radiotherapy following radical hysterectomy for patients with stage IB and IIA cervical cancer. Gynecol Oncol. 1990; 37(3): 390-395, doi: 10.1016/0090-8258(90)90374-t, indexed in Pubmed: 2351324.

32. Kim D, Ki Y, Kim W, et al. Adjuvant external beam radiation and brachytherapy for vaginal resection margin positive cervical cancer. Radiat Oncol J. 2018; 36(2): 147-152, doi: 10.3857/roj.2018.00087, indexed in Pubmed: 29983035.

33. Landoni F, Colombo A, Milani R, et al. Randomized study between radical surgery and radiotherapy for the treatment of stage IB-IIA cervical cancer: 20-year update. J Gynecol Oncol. 2017; 28(3): e34, doi: 10.3802/jgo.2017.28. e34, indexed in Pubmed: 28382797.

34. Landoni F, Maneo A, Colombo A, et al. Randomised study of radical surgery versus radiotherapy for stage lb-lla cervical cancer. Lancet. 1997; 350(9077):535-540, doi: 10.1016/ s0140-6736(97)02250-2, indexed in Pubmed: 9284774.

35. Rose PG, Bundy BN, Watkins EB, et al. Concurrent cisplatin-based radiotherapy and chemotherapy for locally advanced cervical cancer. N Engl J Med. 1999; 340(15): 1144-1153, doi: 10.1056/NEJM199904153401502, indexed in Pubmed: 10202165.

36. Keys HM, Bundy BN, Stehman FB, et al. Cisplatin, radiation, and adjuvant hysterectomy compared with radiation and adjuvant hysterectomy for bulky stage IB cervical carcinoma. N Engl J Med. 1999; 340(15): 1154-1161, doi: 10.1056/NEJM199904153401503, indexed in Pubmed: 10202166.

37. Morris M, Eifel PJ, Lu J, et al. Pelvic radiation with concurrent chemotherapy compared with pelvic and para-aortic radiation for high-risk cervical cancer. $\mathrm{N}$ Engl J Med. 1999; 340(15): 1137-1143, doi: 10.1056/ NEJM199904153401501, indexed in Pubmed: 10202164.

38. Whitney CW, Sause W, Bundy BN, et al. Randomized comparison of fluorouracil plus cisplatin versus hydroxyurea as an adjunct to radiation therapy in stage IIB-IVA carcinoma of the cervix with negative para-aortic lymph nodes: a Gynecologic Oncology Group and Southwest Oncology Group study. J Clin Oncol. 1999; 17(5): 1339-1348, doi: 10.1200/JCO.1999.17.5.1339, indexed in Pubmed: 10334517.

39. Chemoradiotherapy for Cervical Cancer Meta-Analysis Collaboration. Reducing uncertainties about the effects of chemoradiotherapy for cervical cancer: a systematic review and meta-analysis of individual patient data from 18 randomized trials. J Clin Oncol. 2008; 26(35): 5802-5812, doi: 10.1200/JCO.2008.16.4368, indexed in Pubmed: 19001332. 
40. Du XI, Tao J, Sheng Xg, et al. Intensity-modulated radiation therapy for advanced cervical cancer: a comparison of dosimetric and clinical outcomes with conventional radiotherapy. Gynecol Oncol. 2012; 125(1): 151-157, doi: 10.1016/j.ygyno.2011.12.432, indexed in Pubmed: 22198339.

41. Chen SW, Liang JA, Hung YC, et al. Does initial 45Gy of pelvic intensity-modulated radiotherapy reduce late complications in patients with locally advanced cervical cancer? A cohort control study using definitive chemoradiotherapy with high-dose rate brachytherapy. Radiol Oncol. 2013;47(2): 176-184, doi: 10.2478/raon-2013-0011, indexed in Pubmed: 23801915.

42. Wu MH, Chen JH, Tai HC, et al. Intensity-Modulated Radiotherapy with Concurrent Chemotherapy for Elder Cervical Cancers: A Comparison of Clinical Outcomes with Conventional Radiotherapy. Int J Gerontol. 2016; 10(3): 159-163, doi: 10.1016/j.ijge.2016.02.003.

43. Naik A, Gurjar OP, Gupta KL, et al. Comparison of dosimetric parameters and acute toxicity of intensity-modulated and three-dimensional radiotherapy in patients with cervix carcinoma: A randomized prospective study. Cancer Radiother. 2016; 20(5): 370-376, doi: 10.1016/j. canrad.2016.05.011, indexed in Pubmed: 27368915.

44. Gandhi AK, Sharma DN, Rath GK, et al. Early clinical outcomes and toxicity of intensity modulated versus conventional pelvic radiation therapy for locally advanced cervix carcinoma: a prospective randomized study. Int J Radiat Oncol Biol Phys. 2013; 87(3): 542-548, doi: 10.1016/j. ijrobp.2013.06.2059, indexed in Pubmed: 24074927.

45. Kidd EA, Siegel BA, Dehdashti F, et al. Clinical outcomes of definitive intensity-modulated radiation therapy with fluorodeoxyglucose-positron emission tomography simulation in patients with locally advanced cervical cancer. Int J Radiat Oncol Biol Phys. 2010; 77(4): 1085-1091, doi: 10.1016/j.jijrobp.2009.06.041, indexed in Pubmed: 19880262.

46. Lin Y, Chen K, Lu Z, et al. Intensity-modulated radiation therapy for definitive treatment of cervical cancer: a meta-analysis. Radiat Oncol. 2018; 13(1): 177, doi: 10.1186/ s13014-018-1126-7, indexed in Pubmed: 30217165.

47. Cibula D, Pötter R, Planchamp F, et al. The European Society of Gynaecological Oncology/European Society for Radiotherapy and Oncology/European Society of Pathology guidelines for the management of patients with cervical cancer. Radiother Oncol. 2018; 127(3): 404-416, doi: 10.1016/j.radonc.2018.03.003, indexed in Pubmed: 29728273.

48. Dimopoulos JCA, Schirl G, Baldinger A, et al. MRI assessment of cervical cancer for adaptive radiotherapy. Strahlenther Onkol. 2009; 185(5): 282-287, doi: 10.1007/ s00066-009-1918-7, indexed in Pubmed: 19440666.

49. Mazeron R, Petit C, Rivin E, et al. 45 or 50 Gy, Which is the Optimal Radiotherapy Pelvic Dose in Locally Advanced Cervical Cancer in the Perspective of Reaching Magnetic Resonance Image-guided Adaptive Brachytherapy Planning Aims? Clin Oncol (R Coll Radiol). 2016; 28(3): 171-177, doi: 10.1016/j.clon.2015.10.008, indexed in Pubmed: 26547694.

50. Pötter R, Tanderup K, Kirisits C, et al. EMBRACE Collaborative Group. The EMBRACE II study: The outcome and prospect of two decades of evolution within the GECESTRO GYN working group and the EMBRACE studies.
Clin Transl Radiat Oncol. 2018; 9: 48-60, doi: 10.1016/j. ctro.2018.01.001, indexed in Pubmed: 29594251.

51. EMBRACE. https://www.embracestudy.dk/Public/Default. aspx?ReturnUrl=\%2f (11/07/2019).

52. Perez CA, Grigsby PW, Castro-Vita H, et al. Carcinoma of the uterine cervix. I. Impact of prolongation of overall treatment time and timing of brachytherapy on outcome of radiation therapy. Int J Radiat Oncol Biol Phys. 1995; 32(5): 1275-1288, doi: 10.1016/0360-3016(95)00220-S, indexed in Pubmed: 7635767.

53. Petereit DG, Sarkaria JN, Chappell R, et al. The adverse effect of treatment prolongation in cervical carcinoma. Int J Radiat Oncol Biol Phys. 1995; 32(5): 13011307, doi: 10.1016/0360-3016(94)00635-X, indexed in Pubmed: 7635769.

54. Lanciano RM, Pajak TF, Martz K, et al. The influence of treatment time on outcome for squamous cell cancer of the uterine cervix treated with radiation: a patternsof-care study. Int J Radiat Oncol Biol Phys. 1993; 25(3): 391-397, doi: 10.1016/0360-3016(93)90058-4, indexed in Pubmed: 8436516.

55. Girinsky T, Rey A, Roche B, et al. Overall treatment time in advanced cervical carcinomas: a critical parameter in treatment outcome. Int J Radiat Oncol Biol Phys. 1993; 27(5): 1051-1056, doi: 10.1016/0360-3016(93)90522-w, indexed in Pubmed: 8262826.

56. Tanderup K, Fokdal LU, Sturdza A, et al. Effect of tumor dose, volume and overall treatment time on local control after radiochemotherapy including MRI guided brachytherapy of locally advanced cervical cancer. Radiother Oncol. 2016; 120(3): 441-446, doi: 10.1016/j.radonc.2016.05.014, indexed in Pubmed: 27350396

57. Fenkell L, Assenholt M, Nielsen SK, et al. Parametrial boost using midline shielding results in an unpredictable dose to tumor and organs at risk in combined external beam radiotherapy and brachytherapy for locally advanced cervical cancer. Int J Radiat Oncol Biol Phys. 2011; 79(5): 1572-1579, doi: 10.1016/j.jijrobp.2010.05.031, indexed in Pubmed: 20800373.

58. Rajasooriyar C, Van Dyk S, Lindawati M, et al. Reviewing the role of parametrial boost in patients with cervical cancer with clinically involved parametria and staged with positron emission tomography. Int J Gynecol Cancer. 2012; 22(9): 1532-1537, doi: 10.1097/IGC.0b013e31826c4dee, indexed in Pubmed: 23027037.

59. Tewari KS, Monk BJ. Chapter 3 - Invasive Cervical Cancer. In: Di Saia PJ, Creasman W. ed. Clinical Gynecologic Oncology. 8th ed. Mosby, Philadelphia 2012: 51-119.

60. Patel CN, Nazir SA, Khan Z, et al. 18F-FDG PET/CT of cervical carcinoma. AJR Am J Roentgenol. 2011; 196(5): 1225-1233, doi: 10.2214/AJR.10.5084, indexed in Pubmed: 21512096.

61. Marth C, Landoni F, Mahner S, et al. ESMO Guidelines Committee. Cervical cancer: ESMO Clinical Practice Guidelines for diagnosis, treatment and follow-up. Ann Oncol. 2017; 28(suppl_4): iv72-iv83, doi: 10.1093/annonc/mdx220, indexed in Pubmed: 28881916.

62. Rotman M, Pajak TF, Choi K, et al. Prophylactic extendedfield irradiation of para-aortic lymph nodes in stages IIB and bulky IB and IIA cervical carcinomas. Ten-year treatment results of RTOG 79-20. JAMA. 1995; 274(5):387-393, indexed in Pubmed: 7616634. 
63. Rotman M, Choi K, Guse C, et al. Prophylactic irradiation of the para-aortic lymph node chain in stage IIB and bulky stage IB carcinoma of the cervix, initial treatment results of RTOG 7920. Int J Radiat Oncol Biol Phys. 1990; 19(3): 513-521, doi: 10.1016/0360-3016(90)90475-y, indexed in Pubmed: 2211198.

64. Wang W, Liu X, Meng Q, et al. Prophylactic Extended-Field Irradiation for Patients With Cervical Cancer Treated With Concurrent Chemoradiotherapy: A Propensity-Score Matching Analysis. Int J Gynecol Cancer. 2018; 28(8): 1584-1591, doi: 10.1097/IGC.0000000000001344, indexed in Pubmed: 30153215.

65. Haie C, Pejovic MH, Gerbaulet A, et al. Is prophylactic paraaortic irradiation worthwhile in the treatment of advanced cervical carcinoma? Results of a controlled clinical trial of the EORTC radiotherapy group. Radiother Oncol. 1988; 11(2): 101-112, doi: 10.1016/0167-8140(88)90245-9, indexed in Pubmed: 3281186.

66. Eifel PJ, Winter K, Morris M, et al. Pelvic irradiation with concurrent chemotherapy versus pelvic and para-aortic irradiation for high-risk cervical cancer: an update of radiation therapy oncology group trial (RTOG) 90-01. J Clin Oncol. 2004; 22(5): 872-880, doi: 10.1200/JCO.2004.07.197, indexed in Pubmed: 14990643.

67. Osborne EM, Klopp AH, Jhingran A, et al. Definitive Extended-Field Radiation Therapy for Cervical Cancer Patients With Para-Aortic Lymph Node Metastases. Int J Radiat Oncol Biol Phys. 2015; 93(3): S202-S203, doi: 10.1016/j.jjrobp.2015.07.485.

68. Vargo JA, Kim H, Choi S, et al. Extended field intensity modulated radiation therapy with concomitant boost for lymph node-positive cervical cancer: analysis of regional control and recurrence patterns in the positron emission tomography/computed tomography era. Int J Radiat Oncol Biol Phys. 2014; 90(5): 1091-1098, doi: 10.1016/j.ijrobp.2014.08.013, indexed in Pubmed: 25303889.

69. Bacorro W, Dumas I, Escande A, et al. Dose-volume effects in pathologic lymph nodes in locally advanced cervical cancer. Gynecol Oncol. 2018; 148(3): 461-467, doi: 10.1016/j.ygyno.2017.12.028, indexed in Pubmed: 29325690.

70. Grigsby PW, Singh AK, Siegel BA, et al. Lymph node control in cervical cancer. Int J Radiat Oncol Biol Phys. 2004; 59(3): 706-712, doi: 10.1016/j.jirobp.2003.12.038, indexed in Pubmed: 15183474.

71. Wakatsuki M, OhnoT, Kato S, et al. Impact of boost irradiation on pelvic lymph node control in patients with cervical cancer. J Radiat Res. 2014; 55(1): 139-145, doi: 10.1093/ jrr/rrt097, indexed in Pubmed: 23912599.

72. Orton C, Seyedsadr M, Somnay A. Comparison of high and low dose rate remote afterloading for cervix cancer and the importance of fractionation. Int J Radiat Oncol Biol Phys. 1991; 21(6): 1425-1434, doi: 10.1016/03603016(91)90316-v, indexed in Pubmed: 1938550.

73. Patel FD, Sharma SC, Negi PS, et al. Low dose rate vs. high dose rate brachytherapy in the treatment of carcinoma of the uterine cervix: a clinical trial. Int J Radiat Oncol Biol Phys. 1994; 28(2): 335-341, doi: 10.1016/03603016(94)90055-8, indexed in Pubmed: 8276647.

74. Kim H, Rajagopalan MS, Beriwal S, et al. Cost-effectiveness analysis of 3D image-guided brachytherapy compared with $2 \mathrm{D}$ brachytherapy in the treatment of locally advanced cervical cancer. Brachytherapy. 2015; 14(1): 29-36, doi: 10.1016/j.brachy.2014.09.002, indexed in Pubmed: 25443528.

75. Pelloski CE, Palmer M, Chronowski GM, et al. Comparison between CT-based volumetric calculations and ICRU reference-point estimates of radiation doses delivered to bladder and rectum during intracavitary radiotherapy for cervical cancer. Int J Radiat Oncol Biol Phys. 2005; 62(1): 131-137, doi: 10.1016/j.ijrobp.2004.09.059, indexed in Pubmed: 15850913.

76. Lee KK, Lee JY, Nam JMo, et al. High-dose-rate vs. low-dose-rate intracavitary brachytherapy for carcinoma of the uterine cervix: Systematic review and meta-analysis. Brachytherapy. 2015; 14(4): 449-457, doi: 10.1016/j.brachy.2015.02.390, indexed in Pubmed: 25906951.

77. The Transition from 2-D Brachytherapy to 3-D High Dose Rate Brachytherapy: Training Material. Thttps://www. iaea.org/publications/10982/the-transition-from-2-dbrachytherapy-to-3-d-high-dose-rate-brachytherapytraining-material (04/27/2020).

78. Charra-Brunaud C, Harter V, Delannes M, et al. Impact of 3D image-based PDR brachytherapy on outcome of patients treated for cervix carcinoma in France: results of the French STIC prospective study. Radiother Oncol. 2012; 103(3): 305-313, doi: 10.1016/j.radonc.2012.04.007, indexed in Pubmed: 22633469.

79. Tanderup K, Lindegaard JC, Kirisits C, et al. Image Guided Adaptive Brachytherapy in cervix cancer: A new paradigm changing clinical practice and outcome. Radiother Oncol. 2016; 120(3):365-369, doi: 10.1016/j.radonc.2016.08.007, indexed in Pubmed: 27555228.

80. Tanderup K, Georg D, Pötter R, et al. Adaptive management of cervical cancer radiotherapy. Semin Radiat Oncol. 2010; 20(2): 121-129, doi: 10.1016/j.semradonc.2009.11.006, indexed in Pubmed: 20219550.

81. Tanderup K, Viswanathan AN, Kirisits C, et al. Magnetic resonance image guided brachytherapy. Semin Radiat Oncol. 2014; 24(3): 181-191, doi: 10.1016/j.semradonc.2014.02.007, indexed in Pubmed: 24931089.

82. Serban M, Kirisits C, de Leeuw A, et al. EMBRACE Collaborative Group. Ring Versus Ovoids and Intracavitary Versus Intracavitary-Interstitial Applicators in Cervical Cancer Brachytherapy: Results From the EMBRACE I Study. Int J Radiat Oncol Biol Phys. 2020; 106(5): 1052-1062, doi: 10.1016/j.ijrobp.2019.12.019, indexed in Pubmed: 32007365.

83. Kashihara T, Kobayashi K, lijima K, et al. A case report of a patient with bulky uterine cervical neoplasm who achieved complete response with "intentional internal high-dose policy" high-dose-rate interstitial brachytherapy. Medicine (Baltimore). 2020; 99(27): e20860, doi: 10.1097/MD.0000000000020860, indexed in Pubmed: 32629674.

84. Fokdal L, Sturdza A, Mazeron R, et al. Image guided adaptive brachytherapy with combined intracavitary and interstitial technique improves the therapeutic ratio in locally advanced cervical cancer: Analysis from the retroEMBRACE study. Radiother Oncol. 2016; 120(3): 434-440, doi: 10.1016/j.radonc.2016.03.020, indexed in Pubmed: 27113795.

85. Smolic M, Sombroek C, Bloemers MC, et al. Prediction of optimal needle configuration in the first fraction of 
cervix brachytherapy. Phys Imaging Radiat Oncol. 2019; 10: 14-18, doi: 10.1016/j.phro.2019.04.006, indexed in Pubmed: 33458262.

86. Wachter-Gerstner N, Wachter S, Reinstadler E, et al. The impact of sectional imaging on dose escalation in endocavitary HDR-brachytherapy of cervical cancer: results of a prospective comparative trial. Radiother Oncol. 2003; 68(1): 51-59, doi: 10.1016/s0167-8140(03)00083-5, indexed in Pubmed: 12885452.

87. Wachter S, Gerstner N, Lefaza D, et al. 6The impact of MRI on the delineation of gross tumour volume in cervical cancer treatment planning: An interobserver analysis. Radiother Oncol. 2001; 60: S2-S3, doi: 10.1016/s01678140(01)80013-x.

88. Viswanathan AN, Erickson B, Gaffney DK, et al. Comparison and consensus guidelines for delineation of clinical target volume for CT- and MR-based brachytherapy in locally advanced cervical cancer. Int J Radiat Oncol Biol Phys. 2014; 90(2): 320-328, doi: 10.1016/j.jirobp.2014.06.005, indexed in Pubmed: 25304792.

89. Kamran SC, Manuel MM, Cho LP, et al. Comparison of outcomes for MR-guided versus CT-guided high-dose-rate interstitial brachytherapy in women with locally advanced carcinoma of the cervix. Gynecol Oncol. 2017; 145(2): 284-290, doi: 10.1016/j.ygyno.2017.03.004, indexed in Pubmed: 28318644.

90. Mahantshetty U, Naga Ch P, Khadanga CR, et al. A Prospective Comparison of Computed Tomography with Transrectal Ultrasonography Assistance and Magnetic Resonance Imaging-Based Target-Volume Definition During Image Guided Adaptive Brachytherapy for Cervical Cancers. Int J Radiat Oncol Biol Phys. 2018; 102(5): 1448-1456, doi: 10.1016/j.ijrobp.2018.05.080, indexed in Pubmed: 30146092. 